\title{
Influência do aparelho propulsor Twin Block no crescimento mandibular: revisão sistemática da literatura*
}

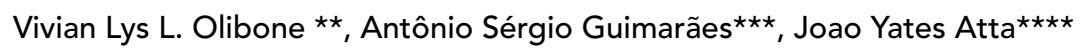

\section{Resumo}

Objetivo: avaliar a eficácia do aparelho ortopédico propulsor mandibular Twin Block quanto ao crescimento mandibular. Metodologia: revisão sistemática da literatura a partir de 1970. Resultados e Conclusões: a maioria dos autores afirmou que houve uma diminuição significativa do ângulo SNA com retroinclinação dos incisivos superiores, o ângulo SNB sofreu aumento com vestibularização dos incisivos inferiores, houve uma resposta tissular positiva nas estruturas da ATM durante o uso do propulsor. As alterações que ocorreram são uma combinação de modificações do côndilo, da fossa mandibular, do osso basal, além de alterações alvéolo-dentárias. Cada modificação estrutural dependeu de uma multiplicidade de fatores em cada indivíduo, como o padrão morfogenético, a idade, o gênero, o padrão funcional, o controle do aparelho e os hábitos orofaciais, entre outros.

Palavras-chave: Twin Block. Crescimento mandibular. Crescimento condilar. Ortopedia funcional. Má oclusão de Classe II.

\section{INTRODUÇÃO}

Há muito tempo, a escolha de estratégias de tratamento - fixo ou funcional - para a correção da má oclusão de Classe II esquelética têm sido motivo de debate entre os ortodontistas e ortopedistas. Desde os anos trinta, os aparelhos funcionais alcançaram grande popularidade na Europa, e mais recentemente em todo o mundo. Grande parte desta popularidade advém de sua presumida habilidade de aumentar o crescimento mandibular nas más oclusões de Classe II associadas à retrusão mandibular. McNamara Jr. ${ }^{17}$ publicou um estudo que teve um grande impacto no mundo ortodôntico, afirmando que em uma amostragem de Classe II (277 casos) a retrusão maxilar foi mais encontrada que a protrusão, e que a característica isolada mais encontrada foi a retrusão mandibular esquelética. Moyers ${ }^{26}$ analisou uma amostra de 610 casos de Classe II e encontrou a metade apresentando retrognatismo mandibular. Portanto, quem utiliza tração extrabucal na maioria dos seus casos de Classe II pode até conseguir bons resultados dentários, mas com o compromisso da estética de seu paciente.

* Resumo da tese (mestrado) apresentada como requisito para obtenção do título de Mestre em Morfologia Aplicada à Área da Saúde / EPM-UNIFESP

** Ortodontista, Mestranda em Morfologia aplicada à Área da Saúde pela UNIFESP/EPM, Professora do Curso de Especialização em Ortodontia do Esquadrão de Saúde da Base Aérea de Campo Grande e do Sindicato dos Odontologistas de Mato Grosso do Sul.

*** Doutor em Ciências da Saúde UNIFESP/EPM. Coordenador da área de Odontologia do Instituto da Cabeça UNIFESP/EPM

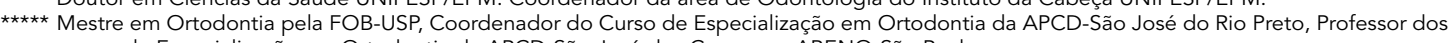
cursos de Especialização em Ortodontia da APCD-São José dos Campos e ABENO-São Paulo. 
Sabe-se que o aparelho Twin Block é considerado dento-suportado e, portanto, pode-se esperar um efeito dentoalveolar como resposta ao tratamento. De acordo com Lund e Sandler ${ }^{15}$, com o uso deste aparelho, o trespasse horizontal foi reduzido pela combinação da lingüalização dos incisivos superiores, com a vestibularização dos incisivos inferiores, além do movimento para frente da mandíbula. Clark ${ }^{6}$ considerou o Twin Block como o aparelho funcional removível mais confortável e aceitável pelo paciente. $\mathrm{O}$ autor observou ainda uma redução no ângulo ANB, um aumento no comprimento efetivo da mandíbula (ArticularGnátio), aumento na altura facial (Násio-Mentoniano), redução na convexidade facial. Aggarwal et al. ${ }^{1}$ observaram um aumento da atividade eletromiográfica atribuído a um reflexo maior de estiramento dos músculos elevadores (masseter e temporal anterior), contribuindo para as contrações isométricas. Os resultados deste estudo reafirmaram a importância do uso em tempo integral dos aparelhos funcionais para que exerçam seu efeito terapêutico máximo por meio da adaptação neuromuscular.

\section{REVISÃO DE LITERATURA}

No primeiro estágio de seu desenvolvimento, o Twin Block foi concebido como um aparelho removível simples, com blocos de mordida que colocavam a mandíbula para frente, visando conseguir correção funcional de uma má oclusão de Classe II, divisão 1. Este princípio básico ainda é aplicado, mas com o passar dos anos ocorreram muitas variações no desenho do aparelho, com objetivo de tratar uma ampla gama de más oclusões. No tratamento da má oclusão de Classe II, divisão 2, o desenho do aparelho é modificado, com a adição de parafusos sagitais, para avançar os dentes anteriores superiores. Outra forma de tratamento de Classe II, divisão 2, adotada em vários pacientes consiste em, primeiramente, alinhar e nivelar os dentes superiores com o aparelho fixo, destravando assim a mordida, para posteriormente utili- zar o Twin Block. O tratamento da má oclusão de Classe III de Angle é conseguido invertendo-se os planos oclusais inclinados, para aplicar um componente de força para adiante no arco superior, além de forçar a mandíbula para trás. $\mathrm{O}$ aparelho também possui um parafuso sagital para avançar os incisivos superiores.

O Twin Block para correção de má oclusão de Classe II é constituído de dois blocos de mordida, um superior e outro inferior, com planos inclinados em $70^{\circ}$. Os dois blocos são desenhados para engrenarem-se de modo que a mandíbula ocupe uma posição mais protruída (Fig. 1).

Os blocos de mordida superior e inferior possuem características particulares, as quais foram descritas por Rondeau ${ }^{34}$. Quando for utilizado parafuso expansor mediano no bloco inferior, o acrílico deve ser estendido até a região lingual dos molares durante a ativação do mesmo. Após o término da ativação, o acrílico pode ser removido, permitindo uma erupção passiva (dentição mista) ou ativa (dentição permanente) dos molares inferiores (Fig. 2).

Em alguns casos, há presença de atresia maxilar e ao fazer o avanço da mandíbula com o aparelho, para correção da Classe II, ocorre o cruzamento da mordida. Para isso, é indicada a Expansão Rápida
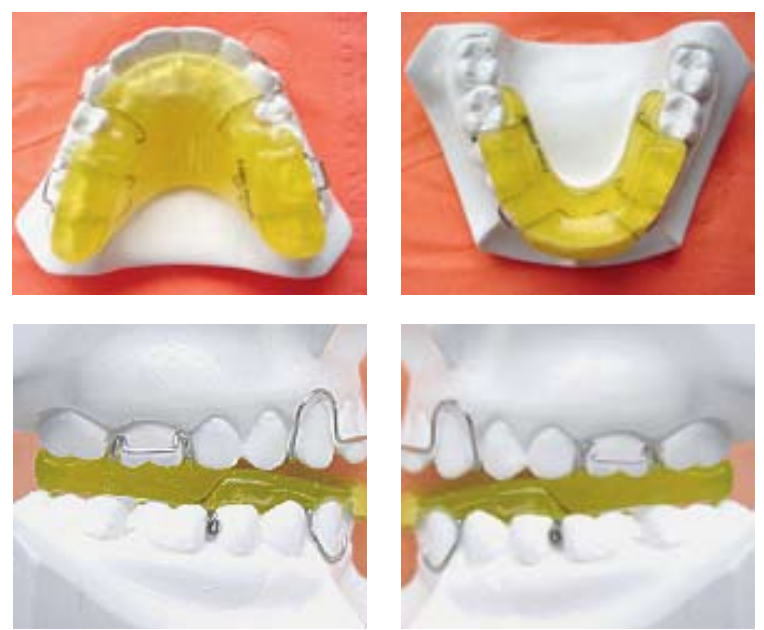

FIGURA 1 - Aparelho Twin Block - plano inclinado de $70^{\circ}$ entre os blocos superior e inferior. 
da Maxila como procedimento prévio à instalação do Twin Block. O passo mais crítico na construção do aparelho ortopédico facial é o registro da mordida construtiva. É ela que determina a quantidade de deslocamento mandibular vertical e horizontal e, portanto, o grau e a direção de ativação do aparelho. A mordida é registrada determinando-se primeiramente a posição fisiológica de repouso da mandíbula e a partir daí a mesma é deslocada verticalmente de $1 \mathrm{a} 4 \mathrm{~mm}$ e horizontalmente de 5 a $8 \mathrm{~mm}$. O deslocamento vertical é usado para que o aparelho seja mantido em posição pelos músculos elevadores da mandíbula, distendidos pelo aparelho que, evitando o retorno da mandíbula à sua posição inicial, transfere a força para a maxila, que se transforma em unidade de ancoragem (Fig. 3). Segundo Clark ${ }^{7}$, os músculos são os "movedores oficiais" no crescimento, e a remodelação óssea está relacionada com os requisitos funcionais da atividade muscular. As linhas medianas superior e inferior devem alinhar-se na colocação para frente da mandíbula, no mesmo relacionamento da oclusão habitual. Se as linhas medianas não coincidem, deve-se determinar onde está o desvio, se na maxila ou na mandíbula.

O Twin Block é usado durante a fase ativa do tratamento por 7 a 9 meses. Durante esta fase há correção parcial do problema vertical. Em casos de sobremordida profunda deve ser desgastado aproximadamente $1,5 \mathrm{~mm}$ do bloco superior, permitindo a erupção dos molares inferiores. $\mathrm{Na}$ dentição mista, os primeiros molares decíduos irrompem passivamente, já na dentição permanente há necessidade do uso de elásticos intermaxilares $1 / 8$, os quais são colocados nos grampos dos primeiros molares superiores até ganchos colados nos molares inferiores. A fase ativa do tratamento com Twin Block é completada quando a sobremordida e sobressaliência estiverem normais, quando os incisivos superiores e inferiores estiverem em contato e quando os molares inferiores ocluírem com os molares superiores.

O dispositivo usado na fase de contenção consiste num aparelho removivel superior com um plano inclinado anterior estendendo-se de canino a canino. Todas as vezes que o paciente deglutir, os incisivos inferiores ocluirão no plano inclinado, ajudando a manter a posição anterior da mandíbula, adquirida durante o tratamento com o Twin Block. O principal propósito da fase de contenção, que dura aproximadamente 6 a 9 meses, é manter a posição anterior da mandíbula, conseguida com o Twin Block e correção da sobremordida. O tempo total de tratamento, incluindo a fase ativa do uso do Twin Block e fase de contenção deve ser de no mínimo 15 a 18 meses, permitindo assim mudanças esqueléticas, musculares e dentárias permanentes.

Clark ${ }^{6}$ relatou que mudanças significantes na aparência facial são observadas com 2 a 3 meses de uso do aparelho funcional Twin Block, isto como resultado de uma adaptação neuromuscular pelo uso contínuo. Os pacientes descreveram o aparelho Twin Block como o mais confortável de todos

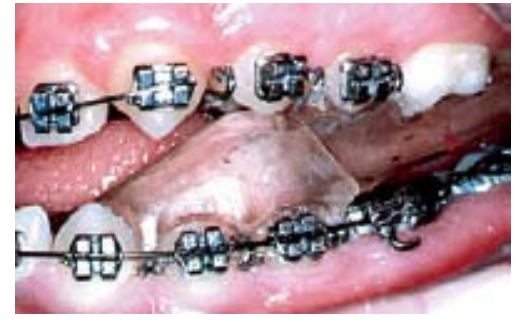

FIGURA 2 - Desgaste do acrílico do bloco superior de 1-2mm para permitir a extrusão dos molares inferiores para correção da sobremordida e nivelamento da curva de Spee.
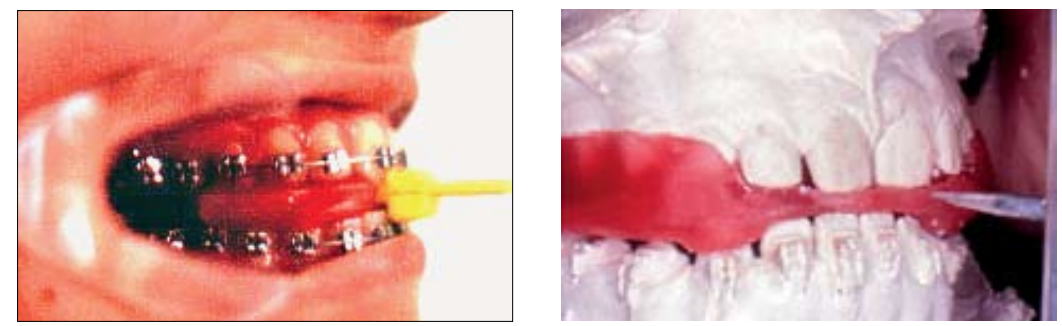

FIGURA 3 - Mordida construtiva com avanço mandibular até topo a topo anterior. 
os aparelhos funcionais que utilizaram.

Frazer $^{11}$ descreveu como vantagens do Twin Block o desenho do aparelho, o qual permite que o paciente adapte-se perfeitamente, podendo ser usado 24 horas por dia, além do mesmo não interferir nas excursões laterais da mandíbula, podendo ser usado no final do surto de crescimento, com algum sucesso.

O objetivo no desenvolvimento da abordagem de tratamento com o aparelho funcional Twin Block, segundo Clark ${ }^{7}$, foi produzir uma técnica que pudesse maximizar a resposta de crescimento à protrusão mandibular funcional, empregando-se um aparelho que é simples, confortável e esteticamente aceitável pelo paciente. Nos primeiros estágios de sua evolução, o Twin Block foi concebido como um aparelho removível simples, com bloco de mordida para colocar a mandíbula para frente.

Clark ${ }^{7}$ relatou que os planos inclinados do aparelho tentam simular os planos oclusais inclinados da dentição natural que constituem mecanismos funcionais fundamentais, pois determinam a relação entre os dentes em oclusão. Se a mandíbula oclui numa relação distal com a maxila, as forças oclusais agem nos dentes inferiores de maneira desfavorável, impedindo o desenvolvimento normal da mandíbula para frente. Os planos inclinados das cúspides dos dentes superiores e inferiores representam o servossistema que, no caso de uma relação de Classe II por retrognatismo mandibular, segura a mandíbula numa posição funcional de oclusão distal. O Twin Block age rapidamente na correção da má oclusão por transmitir as forças oclusais favoráveis através dos planos inclinados que cobrem os dentes posteriores. $\mathrm{O}$ equilíbrio funcional é estabelecido através de um controle neurológico em resposta ao estímulo proprioceptivo constante, influenciando no grau de crescimento ósseo. Yang ${ }^{45}$ relatou que as forças oclusais transmitidas através da dentição com o uso do aparelho propulsor mandibular Twin Block produzem um estímulo proprioceptivo constante, influenciando no padrão de crescimento e na es- trutura trabecular do osso de suporte. O plano inclinado do aparelho induz favoravelmente a direção das forças oclusais, causando um deslocamento mandibular funcional. Lund e Sandler ${ }^{15}$ trataram pacientes com Twin Block por um tempo médio de 1 ano e 2 meses e observaram que não ocorreu restrição significante no crescimento da maxila; houve um aumento de 5,1 mm no Ar-Pog, comparado ao aumento do grupo controle de $2,7 \mathrm{~mm}$. O trespasse horizontal foi diminuído em decorrência dos efeitos dentoalveolares (vestibularização dos incisivos inferiores e lingüalização dos incisivos superiores) e do movimento mesial da mandíbula no grupo tratado. A altura facial anterior aumentou e não foi avaliada qualquer adaptação possivel da fossa glenóide.

Toth e McNamara $\mathrm{Jr}^{38}$ avaliaram pacientes com Twin Block e observaram que houve uma diminuição significante na sobremordida e sobressaliência nos grupos tratados em comparação com o não tratado, o comprimento mandibular e a altura facial anterior aumentaram mais nos grupos tratados do que no controle não tratado e que o aparelho Twin Block corrigiu a Classe II existente através de uma combinação de alterações esqueléticas e dentoalveolares.

Chintakanon et al. ${ }^{5}$, estudando os efeitos do aparelho ortopédico funcional Twin Block na articulação têmporo-mandibular, em pacientes com má oclusão de Classe II, divisão 1 , através do emprego de ressonância magnética, concluíram que a terapia altera a direção do crescimento condilar. Para eles, o côndilo, que estava posicionado inicialmente no topo da eminência articular com o aparelho propulsor, ao final de 6 meses de terapia, retornou para a fossa glenóide; porém, não foram encontradas evidências de remodelação da fossa glenóide e eminência articular. Os autores verificaram através das imagens que nenhum efeito positivo ou negativo foi encontrado na posição do disco articular com o uso do aparelho propulsor mandibular Twin Block, e que o número de crianças que apresentavam deslocamento de disco foi o 
mesmo no início e no final do tratamento.

Baccetti et al. ${ }^{2}$ concluíram que o melhor período para tratamento de pacientes com má oclusão de Classe II por deficiência mandibular é durante ou logo após o início do pico puberal de crescimento e que o uso do aparelho Twin Block nesta fase produz efeitos favoráveis, tais como: grande contribuição esquelética na correção da relação molar, grandes incrementos de crescimento no comprimento total da mandíbula e na altura do ramo, além de um direcionamento mais posterior de crescimento condilar. Os autores destacaram a importância fundamental da avaliação da maturidade esquelética do paciente Classe II a ser tratado com aparelho ortopédico funcional.

Singh e Clark ${ }^{36}$, estudando mudanças morfológicas na mandíbula em pacientes com má oclusão de Classe II, divisão 1 por retrognatismo mandibular, nas fases pré e pós-puberal, usando o aparelho propulsor mandibular Twin Block, concluíram que o crescimento condilar, a remodelação do processo coronóide e a osteogênese no corpo e na região dentoalveolar podem refletir na correção da displasia esquelética. Para os autores, o Twin Block é um aparelho versátil e efetivo para a correção da má oclusão de Classe II.

Parkin, McKeown e Sandler ${ }^{32}$ compararam as modificações dentárias e esqueléticas para correção da Classe II, através de dois modelos de aparelho Twin Block (TBl = com arco labial; TB2 = com torque nos incisivos centrais superiores e AEB tração alta). O grupo TB2 mostrou um aumento significante na restrição do crescimento maxilar quando comparado ao grupo TBl. Ocorreu uma redução significativamente maior no ângulo ANB no grupo TB2. A relação altura facial anterior inferior - altura facial anterior total aumentou no grupo TBl e permaneceu inalterada no grupo TB2 pela adição do AEB de tração alta ao aparelho Twin Block, permitindo assim efetivo controle vertical e sagital da maxila. A inclinação dentoalveolar dos incisivos superiores (retroinclinação) e dos incisivos inferiores (proclinação) ocorreu nos 2 grupos.

O'Brien et al..$^{28}$ avaliaram a efetividade dos aparelhos Herbst e Twin Block no tratamento de má oclusão de Classe II, divisão 1 . O total de pacientes era de 215 com idade entre 11 e 14 anos, os quais foram tratados com aparelho de Herbst ou com Twin Block. Não houve diferença no tempo de tratamento nem nas mudanças esqueléticas e dentárias entre os aparelhos, todavia os melhores resultados encontrados foram nas meninas do que nos meninos, devido ao grau de cooperação com o uso dos aparelhos.

\section{MÉTODO}

Foi realizada busca nas bases de dados eletrônicas: MEDLINE (de 1970 a 2003) e BBO, com as palavras chave "twin-block", "crescimento mandibular", "crescimento condilar", "ortopedia funcional", "má oclusão Classe II divisão 1", "retrognatismo mandibular", como descritor de assunto, todas em português e inglês. Os critérios de inclusão utilizados foram as línguas inglesa, espanhola e portuguesa e trabalhos que abordassem conceitos e variáveis, além de discussões sobre o tema abordado. Foram incluídos, também, trabalhos que relacionavam outros tipos de aparelhos ortopédicos funcionais. Foram excluídos trabalhos que apenas descreviam a técnica de confecção do aparelho em questão. Em razão da necessidade de recuperação de conceitos mais anteriores dos termos utilizados, foi feita uma busca por referências bibliográficas dos trabalhos selecionados para que pudéssemos ter acesso a trabalhos anteriores a 1970. Os trabalhos relacionados foram distribuídos conforme o quadro 1 .

A revisão da literatura foi realizada com vistas a uma abordagem sistemática, com a intenção de obter o caráter evolutivo do uso dos aparelhos ortopédicos funcionais, em especial o aparelho Twin Block.

\section{DISCUSSÃO}

Com intuito de melhorar o relacionamento maxilo-mandibular numa má oclusão de Classe II, 
Influência do aparelho propulsor Twin Block no crescimento mandibular: revisão sistemática da literatura

\begin{tabular}{|c|c|c|c|}
\hline Base de dados & Encontrados & Selecionados & Incluídos para estudo \\
\hline Medline (1970-1979) & 11 & 7 & $6^{4,17,18,25,29,37}$ \\
\hline Medline (1980-1989) & 28 & 15 & 11 3,6,19,20,21,22,27,3,30,31,41,44 \\
\hline Medline (1990-1999) & 38 & 25 & $13^{1,8,9,11,11,13,13,14,15,34,35,38,40,45}$ \\
\hline Medline (2000-2003) & 19 & 16 & $9^{2,5,2,23,28,32,3,36,39,42,43}$ \\
\hline BBO & 12 & 8 & $4^{10,16,24,33}$ \\
\hline Capítulo de livro & 6 & 6 & $2^{7,26}$ \\
\hline Total & 114 & 77 & 45 referências \\
\hline
\end{tabular}

Quadro 1 - Bases de dados consultadas, $\mathrm{n}^{0}$ de publicações encontradas e selecionadas, livros incluídos para estudo.

onde na maioria das vezes o problema está localizado na mandíbula que se acha pouco desenvolvida ou retroposicionada, como comprovou McNamara Jr. et al. ${ }^{21}$, é que surgiram os aparelhos ortopédicos funcionais propulsores mandibulares. A resposta clínica observada após a instalação do Twin Block é análoga às alterações observadas em animais experimentais que usam planos inclinados fixos, como descrito por McNamara Jr. ${ }^{19}$. Stutzmann e Petrovic ${ }^{37}$ que, investigando os efeitos do deslocamento mandibular funcional sobre o crescimento mandibular em animais experimentais, demonstraram que estes apresentaram melhora no crescimento mandibular quando comparado aos animais controle. Os efeitos da propulsão mandibular em ratos também foram estudados por Charlier, Petrovic e Stutzmann ${ }^{4}$ que comprovaram a existência de um crescimento adicional de cartilagem condilar. McNamara Jr. e Carlson ${ }^{18}$ também obtiveram respostas positivas no crescimento da cartilagem condilar em macacos rhesus juvenis. Ao utilizar planos inclinados em coelhos, Moss $^{25}$ obteve respostas favoráveis no crescimento condilar. O efeito positivo do aparelho propulsor mandibular na proliferação do tecido condilar, assim como a remodelação na porção anterior da fossa mandibular e aumento no comprimento da mandíbula, foi encontrado por Woodside, Metaxas e Altuna $^{44}$ em grupo de macaca fascicularis jovens. O grau de maturidade do animal é importante fator moderador na capacidade de resposta do côndilo mandibular a uma alteração da posição mandibular pelo crescimento, como elucidou McNamara Jr. ${ }^{17}$ e foi confirmado por Woodside et $\mathrm{al} .{ }^{44}$. Enquanto existir um pouco de capacidade adaptativa, ainda pode estar presente, nas articulações têmporo-mandibulares de animais adultos jovens, uma certa magnitude de potencial de crescimento mandibular, sendo limitado e altamente variável, como mostraram $\mathrm{McNa}$ mara Jr. et al. 20,22. O mesmo não foi relatado por Woodside et al. ${ }^{44}$, em experimento no qual os primatas adultos jovens não mostraram resposta de crescimento condilar. Moro, Urias ${ }^{24}$; Ruf, Pancherz ${ }^{35}$; Tumer e Gultan ${ }^{40}$ concordam que a melhor época para estímulo do crescimento condilar com o uso de aparelho propulsor mandibular é durante o período de máximo crescimento puberal. Já Baccetti et al. ${ }^{2}$ afirmam que o melhor período para tratamento da Classe II por deficiência mandibular com o Twin Block é durante ou logo após o início do pico puberal de crescimento. Discordando dos autores supra citados, Frazer ${ }^{11}$ propôs o uso Twin Block no final do surto de crescimento, com sucesso. Com relação à estabilidade, Petrovic, Stutzmann, Lavergne ${ }^{33}$ e Pancherz ${ }^{31}$ concordam que a mesma depende de uma boa intercuspidação dos dentes superiores e inferiores ao final do tratamento.

O tratamento com aparelho propulsor mandibular leva a um aumento do fluxo sangüíneo na zona bilaminar, propiciando um aumento na taxa de crescimento da cartilagem condilar, como afirmaram Moro e Urias ${ }^{24}$. Martins-Ortiz ${ }^{16}$ relatou 
que o deslocamento condilar com o aparelho propulsor mandibular provoca alterações viscoelásticas nos tecidos moles retrodiscais, provocando por transdução a neoformação óssea na fossa e côndilo mandibular. Voudouris e Kuftinec ${ }^{42}$ também relataram que a força dos tecidos viscoelásticos retrodiscais pode afetar o crescimento do côndilo, como resultado da ação do deslocamento ortopédico anterior com o uso do Twin Block, havendo transdução da força para a camada de fibrocartilagem que reveste a cabeça da mandíbula e através do aumento da formação óssea endocondral, novo osso é encontrado na fossa e côndilo mandibular. Clark ${ }^{7}$ afirmou que dentro de poucos dias da instalação do Twin Block a posição do equilíbrio muscular é alterada de tal modo que o paciente passa a sentir dor quando retrai a mandíbula. Isto foi descrito como "resposta pterigóidea" por McNamara Jr. ${ }^{19}$ e Petrovic, Stutzmann e Lavergne ${ }^{33}$, ou a formação de uma "zona de tensão" distal ao côndilo por Woodside et al. ${ }^{44}$.

Alguns autores ${ }^{23,32}$ observaram que após o tratamento com propulsor mandibular Twin Block em indivíduos portadores de má oclusão de Classe II, divisão 1 dentária e/ou esquelética, ângulo ANB maior que 4 graus, sobremordida profunda e no pico de crescimento puberal, o crescimento maxilar foi redirecionado ou inibido, pois o ângulo SNA foi reduzido significativamente, discordando do que foi observado por Lund e Sandler ${ }^{15}$. O trespasse horizontal foi corrigido através do crescimento mandibular e do movimento mesial dos incisivos inferiores ${ }^{15,23,32,38,39}$. Foi observado também uma retroinclinação dos incisivos superiores $^{13,15,23,32,39}$ e a altura facial ântero-inferior sofreu aumento após o uso do aparelho propulsor $^{12,13,15,32,38}$. Tumer e Gultan ${ }^{40}$ concordaram que houve um aumento do ângulo goníaco e do plano mandibular. Alterações nos tecidos moles faciais, com redução da convexidade do perfil mole foram relatadas por Clark ${ }^{6}$, Rondeau ${ }^{34}$ e Yang ${ }^{45}$. Illing, Morris e Lee ${ }^{12}$ observaram que a posição do lábio superior permaneceu estável, porém o lábio inferior protruiu e aumentou de comprimento. Com o uso de outros tipo de aparelhos ortopédicos funcionais também foram observadas as mesmas alterações dentoesqueléticas 3,8,9,10, 24, 27,29,30,31,41,43.

Ao comparar os aparelhos Twin Block e Fränkel usados na correção da Classe II, Toth e McNamara $\mathrm{Jr}^{38}$ observaram que ambos diminuíram a sobremordida e sobressaliência com a mesma eficiência, porém, em relação ao aumento do comprimento mandibular, o Twin Block aumentou em média $3 \mathrm{~mm}$ comparado a $1,9 \mathrm{~mm}$ obtido com o uso do Fränkel; a altura facial anterior aumentou mais com o uso do Twin Block. Tumer e Gultan ${ }^{40}$ avaliaram e compararam resultados de dois tipos de aparelhos - Twin Block e monobloco - concluindo que o segundo apresentou maior grau de retrusão dos incisivos superiores, e o primeiro maior grau de inclinação vestibular dos incisivos inferiores; no grupo com Twin Block houve uma melhor resposta de crescimento mandibular e condilar em comparação ao grupo que usou o monobloco. Illing, Morris e Lee ${ }^{12}$, comparando o Twin Block com o Bionator, observaram que mudanças favoráveis estatisticamente significantes ocorreram em maior número no grupo tratado com o Twin Block. O'Brien et al. ${ }^{28}$, avaliando os aparelhos Herbst e Twin Block, relataram que não houve diferença no tempo de tratamento nem nas mudanças esqueléticas e dentárias entre os dois aparelhos, contudo melhores resultados foram encontrados nas meninas do que nos meninos, devido ao grau de cooperação com o uso dos aparelhos.

Segundo Clark ${ }^{6}$, uma das maiores vantagens do Twin Block quando comparado a outros aparelhos funcionais é que ele foi desenvolvido para ser usado o tempo todo, inclusive durante a prática de esportes (exceto natação), além de a mandíbula poder realizar livremente as excursões anterior e laterais. Frazer ${ }^{11}$ concorda que o desenho do aparelho permite que o paciente adapte-se perfeitamente e enfatiza que o Twin Block não interfere nas excursões laterais da mandíbula. Yang ${ }^{45}$ também considera como vantagem do aparelho 
a presença dos planos inclinados, os quais induzem favoravelmente a direção das forças oclusais, traduzindo-se como um estímulo proprioceptivo constante, contribuindo assim para o crescimento mandibular. Kumar, Sidhu, Kharbanda ${ }^{14}$ e Clark ${ }^{7}$ concordam que os planos inclinados do Twin Block constituem mecanismos funcionais fundamentais ao crescimento mandibular.

\section{CONCLUSÕES}

Após a análise da revisão de literatura pudemos concluir que:

1) O crescimento das dimensões mandibulares, assim como do côndilo, foram significantemente maiores nos grupos tratados com aparelho ortopédico funcional Twin Block, em relação aos grupos controles.
2) A maior parte dos autores afirmou que o crescimento maxilar é significativamente influenciado pelo tratamento com Twin Block, indicando uma restrição no seu deslocamento anterior.

3) O aparelho propulsor mandibular Twin Block propiciou uma melhora significativa na relação maxilomandibular e na convexidade facial, porém com aumento na altura facial ântero-inferior.

4) Os incisivos inferiores sofreram vestibularização, enquanto os incisivos superiores retroinclinaram durante o uso do aparelho ortopédico Twin Block.

5) A maioria dos autores recomenda o uso do aparelho na fase de pico de crescimento puberal.

Enviado em: Março de 2004 Revisado e aceito: Abril de 2005

\title{
Influence of the Twin Block propulsor appliance in the mandibular growth: systematic review of literature
}

\begin{abstract}
Objective: to verify the efficiency of the mandibular propulsor orthopedic appliance Twin Block in the mandibular growth. Methodology: systematic review of literature since 1970. Results and Conclusions: the majority of the authors agreed with a significant reduction of the SNA angle with retroclination of the upper incisors, an increase of the SNB angle with proclination of the lower incisors and there was a positive tissue response on the TMJ during the use of the appliance. The alterations were the combination of modifications on the condyle, the mandibular fossa, the basal bone and dentoalveolar alterations. The exact role of the structures depend on a multiplicity of factors in each individual such as morphogenetic pattern, age, gender, functional pattern, control of the appliance and habits, among others.
\end{abstract}

Key words: Twin Block. Mandibular growth. Condylar growth. Functional orthopedic. Class II malocclusion.

\section{REFERÊNCIAS}

1. AGGARWAL, P. et al. Muscle response to the Twin Block appliance: electromyographic study of the masseter and anterior temporal muscles. Am J Orthod Dentofacial Orthop, St. Louis, v. 116 , no. 4 , p. $405-414$, Oct. 1999

2. BACCETTI, T. et al. Treatment timing for Twin Block therapy. Am J Orthod Dentofacial Orthop, St. Louis, v. 118, no. 2, p. 159-170, Aug. 2000

3. BOLMGREN, G. A.; MOSHIRI, F. Bionator treatment in Class II, division 1. Angle Orthod, Appleton, v. 56, no. 3, p. 255-262, 1986.
4. CHARLIER, J. P.; PETROVIC, A.; STUTZMANN, J. Effects of mandibular hyperpropulsion on the prechondroblastic zone of young rat condyle. Am J Orthod, St. Louis, v. 55, no. 1, p. 71-74,1969.

5. CHINTAKANON, K. et al. Effects of Twin Block therapy on protrusive muscle functions. Am J Orthod Dentofacial Orthop, St. Louis, v.118, no. 4, p. 392-396, 2000.

6. CLARK, W. J. The Twin-Block technique. A functional orthopedic appliance system. Am J Orthod Dentofacial Orthop St. Louis, v. 93, no.1, p. 1-18, 1988

7. CLARK, W. J. Twin Block functional therapy: applications in dentofacial orthopedics. London; Baltimore: Mosby-Wolfe, c1995. p. 272.

8. COURTNEY, M.; HARKNESS, M.; HERBISON, P. Maxillary and cranial base changes during treatment with functional applian- 
ces. Am J Orthod Dentofacial Orthop, St. Louis, v. 109, no. 6, p. 616-624, 1996.

9. CROFT, R. S.; BUSCHANG, P. H.; ENGLISH, J. D.; MEYER, R A cephalometric and tomographic evoluation of Herbst treatment in the mixed dentition. Am J Orthod Dentofacial Orthop, St. Louis, v. 116, no. 4, p. 435-443, 1999.

10. CRUZ, K. S.; HENRIQUES, J. F. C.; DAINESI, E. A.; JANSON, G. Efeitos dos aparelhos funcionais na correção da má oclusão de classe II. R Dental Press Ortodon Ortop Facial, Maringá, v. 5, n. 4, p. $43-52,2000$

11. FRAZER, H. An introduction to modified Twin Block appliance therapy (M.T.B.A.T.). Part I - Sound basics. Funct Orthod, Winchester, v. 11, no. 3, p. 30-32, 36-41, 1994.

12. ILLING, H. M.; MORRIS, D. O.; LEE, R. T. A prospective evaluation of Bass, Bionator and Twin Block appliances. Part I - The hard tissues. Eur J Orthod, Oxford, v. 20, no. 5, p. 501-516, 1998 a.

13. ILLING, H. M.; MORRIS, D. O.; LEE, R. T. A prospective evaluation of Bass, Bionator and Twin Block appliances. Part II - The soft tissues. Eur J Orthod, London, v. 20, no. 6, p. 663-684, 1998b.

14. KUMAR, S.; SIDHU, S.S.; KHARBANDA, O. P. A cephalometric evaluation of the dental and facial-skeletal effects using the Bionator with stepwise protrusive activations. J Clin Pediatr Dent, Birmingham, v. 20, no. 2, p.101-108, 1996.

15. LUND, D. I.; SANDLER, P. J. The effects of Twin Blocks: a prospective controlled study. Am J Orthod Dentofacial Orthop, St. Louis, v. 113, no. 1, p.104-110, 1998.

16. MARTINS-ORTIZ, M. F. Alterações microscópicas da cavidade glenóide induzidas pelo uso de aparelhos funcionais. R Dental Press Ortodon Ortop Facial, Maringá, v. 6, no. 5, p.125-132, 2001.

17. McNAMARA JR., J. A. Neuromuscular and skeletal adaptations to altered function in the orofacial region. Am J Orthod, St. Louis, v. 64, no. 6, p. 578-606, 1973.

18. McNAMARA JR., J. A.; CARLSON, D. S. Quantitative analysis of temporomandibular joint adaptations to protrusive function. Am J Orthod, St. Louis, v. 76, no. 6, p. 593-611, 1979.

19. McNAMARA JR., J. A. Functional determinants of craniofacial size and shape. Eur J Orthod, Oxford, v. 2, no. 1, p. 131-159, 1980.

20. McNAMARA JR., J. A.; HINTON, R. J.; HOFFMAN, D. L. Histologic analysis of temporomandibular joint adaptation to protrusive function in young adult rhesus monkeys (Macaca mulatta). Am J Orthod, St. Louis, v. 82, no. 4, p.288-298, 1982.

21. McNAMARA JR., J. A. et al. Skeletal and dental changes following functional regulator therapy on Class II patients. Am J Orthod, St. Louis, v. 88, no. 2, p. 91-110, 1985.

22. McNAMARA JR., J. A.; BRYAN, F. A. Long-term mandibular adaptations to protrusive function: an experimental study in Macaca mulatta. Am J Orthod, St. Louis, v. 92, no. 2, p. 98-108, 1987.

23. MILLS, C. M.; McCULLOCH, K. J. Posttreatment changes after successful correction of Class II malocclusions with the Twin Block appliance. Am J Orthod Dentofacial Orthop, St. Louis, v. 118, no. 1, p. 24-33, 2000.

24. MORO, A.; URIAS, D. Crescimento condilar: alterações frente à propulsão mandibular. Ortodontia, São Paulo, v. 27, n. 2, p. 78-97, 1994.

25. MOSS, M. L. Functional analysis of human mandibular growth. J Prosthet Dent, St. Louis, v. 10, no. 6, p.1149-1159, 1960.

26. MOYERS, R. E. Ortodontia. 4. ed. Rio de Janeiro: Guanabara Koogan, 1991. p. 483.

27. NIELSEN, I. L. Facial growth during treatment with function regulator appliance. Am J Orthod, St. Louis, v. 85, no. 5, p. 401-410, 1984.

28. O'BRIEN, K. et al. Effectiveness of treatment for Class II malocclusion with the Herbst and Twin-block appliances: a randomized, controlled trial. Am J Orthod Dentofacial Orthop St. Louis, v. 124, no. 2, p. 128-137, Aug. 2003.

29. PANCHERZ, H. Treatment of Class II malocclusions by jumping the bite with the Herbst appliance. Am J Orthod, St. Louis, v. 76 , no. 4 , p. 423-442, 1979.

30. PANCHERZ, $\mathrm{H}$. The mechanism of Class II corretion in Herbst appliance treatment. Am J Orthod, St. Louis, v. 82, no. 2, p.104-113, 1982.

31. PANCHERZ, $H$. The Herbst appliance: its biologic effects and clinical use. Am J Orthod, St. Louis, v. 87, no. 1, p. 1-8, 1985.

32. PARKIN, N. A.; McKEOWN, H. F.; SANDLER, P. J. Comparison of 2 modifications of the Twin Block appliance in matched Class II samples. Am J Orthod Dentofacial Orthop, St. Louis, v. 119, no. 6, p. 572-577, 2001.

33. PETROVIC, A. G.; STUTZMANN, J. J.; LAVERGNE, J. Efeito dos aparelhos funcionais sobre a cartilagem do côndilo mandibular. Ortodontia, São Paulo, v. 24, n. 2, p. 64-81, 1991.

34. RONDEAU, B. Twin Block appliance. Funct Orthod, Winchester, v. 12, no. 2, p.16-21, 1995

35. RUF, S.; PANCHERZ, H. Temporomandibular joint remodeling in adolescents and young adults during Herbst treatment: a prospective longitudinal magnetic resonance imaging and cephalometric radiographic investigation. Am J Orthod Dentofacial Orthop, St. Louis, v. 115, p. 607-618, 1999.

36. SINGH, G. D.; CLARK, W. J. Localization of mandibular changes in patients with Class II division 1 malocclusions treated with Twin Block appliances: finite element scaling analysis. Am J Orthod Dentofacial Orthop, St. Louis, v. 119, no. 4, p. 419-425, 2001.

37. STUTZMANN, J.; PETROVIC, A. Intrinsic regulation of the condylar cartilage growth rate. Eur J Orthod, Oxford, v. 1, p. 41-54, 1979.

38. TOTH, L. R.; McNAMARA JR., J. A. Treatment effects produced by the Twin Block appliance and the FR-2 appliance of Fränkel compared with an untreated Class II sample. Am J Orthod Dentofacial Orthop, St. Louis, v. 116, no. 6, p. 597-609, 1999.

39. TRENOUTH, M. J. Cephalometric evaluation of the Twin Block appliance in the treatment of Class II, Division 1 malocclusion with matched normative growth data. Am J Orthod Dentofacial Orthop, St. Louis, v. 117, no. 1, p. 54-59, 2000.

40. TUMER, N.; GULTAN, A. S. Comparison of the effects of monoblock and Twin-block appliances on the skeletal and dentoalveolar structures. Am J Orthod Dentofacial Orthop, St. Louis, v. 116 , no. 4, p. 460-468, 1999.

41. VARGERVIK, K.; HARVOLD, E. P. Response to activator treatment in Class II malocclusions. Am J Orthod, St. Louis, v. 88, no. 3, p. 242-251, 1985.

42. VOUDOURIS, J. C.; KUFTINEC, M. M. Improved clinical use of Twin block and Herbst as a result of radiating viscoelastic tissue forces on the condyle and fossa in treatment and long-term retention: growth relativity. Am J Orthod Dentofacial Orthop, St. Louis, v. 117, no. 3, p. 247-266, 2000.

43. VOUDOURIS, J. C.; WOODSIDE, D. G.; ALTUNA, G.; ANGELOPOULOS, G.; BOURQUE, P. J.; LACOUTURE, C. Y. Condyle-fossa modifications and muscle interactions during Herbst treatment. Part 2. Results and conclusions. Am J Orthod Dentofacial Orthop, St. Louis, v. 124, no.1, 2003.

44. WOODSIDE, D. G. et al. The influence of functional appliance therapy on glenoid fossa remodeling. Am J Orthod, St. Louis, v. 92, no. 3, p.181-198, 1987.

45. YANG, K. H. Modified Twin Blocks: fabrication method and use in a child with Class II malocclusion. J Clin Pediatr Dent, Birmingham, v. 20, no. 3, p.189-195, 1996.

\section{Endereço para correspondência}

Vivian Lys L. Olibone

Rua Maracajú, 1062 - apto 201 B - Centro

Campo Grande - MS

CEP: 79.002-212

E-mail: vlolibone@yahoo.com.br; viepc@brturbo.com.br 